\title{
Effect of KOB03, a polyherbal medicine, on ovalbumin-induced allergic rhinitis in guinea pigs
}

\author{
Hyo Won Jung ${ }^{1}$, Jin Ki Jung ${ }^{2}$, Young Ho Kim', Jong-Seong Kang ${ }^{3}$ and Yong-Ki Park, ${ }^{1 *}$
}

\begin{abstract}
Background: $\mathrm{KOBO3}$ is a polyherbal medicine that originated from the oriental prescription for the treatment of chronic allergic diseases such as rhinitis and asthma. This study aims to evaluate the effect of KOBO3 on ovalbumin (OVA)-induced allergic rhinitis (AR) in guinea pigs.

Methods: Hartley guinea pigs were sensitized to OVA by intraperitoneal injection on days 0, 7, and 14 and challenged with intranasal exposure to OVA three times for 7 days after the last sensitization. KOBO3 at doses of 200 and $500 \mathrm{mg} / \mathrm{kg}$ were orally administrated to guinea pigs once daily during challenge. The serum levels of histamine, OVA-specific immunoglobulin (Ig) E, eosinophil cationic protein (ECP) and cytokines (TNF-a, IL-4 and IFN- $\gamma$ ) in OVA sensitization/challenge-induced AR guinea pigs were measured. We also observed histological changes in nasal tissues of AR guinea pigs by staining with H\&E, Periodic acid-Schiff, and toluidine blue.
\end{abstract}

Results: The administration of KOB03 at a dose of $500 \mathrm{mg} / \mathrm{kg}$ significantly decreased the serum levels of histamine $(P=0.001)$, OVA-specific lgE $(P=0.0017)$, ECP $(P=0.008)$, and TNF-a $(P=0.0003)$ in OVA-sensitized/challenged guinea pigs compared with controls. KOB03 significantly decreased the serum levels of a Th2 cytokine, IL-4 $(P=0.017)$, while significantly increasing the levels of a Th1 cytokine, IFN- $\gamma(P=0.0006)$ in OVA-sensitized/challenged guinea pigs compared with controls. In addition, KOB03 suppressed the epithelial destruction, goblet cell hyperplasia and eosinophilic infiltration into nasal mucosa associated with AR.

Conclusion: $\mathrm{KOBO3}$ may regulate allergic inflammation in AR by inhibiting nasal damage, the release of allergic mediators and modulating the balance of Th1/Th2 cytokines.

\section{Background}

Allergic rhinitis (AR) is an immunoglobulin (Ig) Emediated inflammatory disease caused by the inflammation of airway mucosa with hypersensitivity resulting from seasonal or perennial responses to specific allergens. It is characterized by a local influx of eosinophils with clinical symptoms including nasal rubbing, sneezing, rhinorrhea, lacrimation, nasal congestion and obstruction [1,2]. AR also triggers systemic inflammation and is associated with various co-morbid conditions such as asthma, nasal polyposis, rhinosinusitis, serous otitis media and sleep disorders [3]. The inflammatory response in the nasal mucosa includes mast cell-mediated allergic responses and a late

\footnotetext{
* Correspondence: yongki@dongguk.ac.kr

'Oriental Medicine R\&D Center, Dongguk University, Gyeongju 780-714, Republic of Korea

2Department of Herbology, College of Oriental Medicine, Dongguk University, Seokjang-Dong 707, Gyeongju 780-714, Republic of Korea Full list of author information is available at the end of the article
}

phase reaction characterized by inflammatory recruitment of secondary effector cells such as eosinophils, basophils, and $\mathrm{T}$ cells expressing T-helper 2 (Th2) cytokines including interleukin (IL)-4 (a switch factor for IgE synthesis) and IL-5 (an eosinophil growth factor that promotes allergic inflammation) [4]. In AR, mast cells release inflammatory mediators such as IL-4, IL-5, IL-6, IL-8, IL-12 and TNF- $\alpha$ when activated by IgE-dependent mechanisms [5]. Basophils and eosinophils are also important for allergic inflammation and mainly function in the last phase allergic response. $\mathrm{T}$ cells are essential for the regulation and coordination of the adaptive immune response in allergic disease. Th1 T cells release IL-2 and IFN- $\gamma$ and are involved in delayed type hypersensitivity whereas Th2 T cells release IL- 4 and IL-5 and mediate IgE-mediated allergic inflammation $[5,6]$. Therefore, these cells are considered as major targets for basic and therapeutic research.

In general, the therapeutic principles for AR treatment are to avoid allergens/triggering factors, and symptomatic

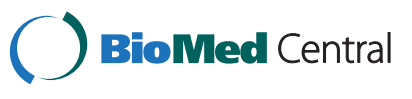


treatment using different drugs such as antihistamines, decongestants, cromolyn sodium, leukotriene modifiers, nasal glucocorticoids, nasal atropine and allergen immunotherapy (also known as allergy shots), to reduce an individual's sensitivity to the allergen [5]. Although pharmacotherapy is greatly required, the current treatment for AR is not ideal, as none of these treatments is sufficiently efficacious for nasal obstruction when given as monotherapy [6]. Recently, with a growing global interest in natural drugs, the search for appropriate anti-allergic agents has focused on medicinal plants that are traditionally used in oriental clinics for the treatment of allergic diseases [7]. KOB03 (Table 1) is a polyherbal medicine derived from the oriental prescription for the treatment of hyperhidrosis and allergic diseases such as rhinitis, asthma and itching [8-11].

This study aims to evaluate the effect of КОВ03 on ovalbumin (OVA) sensitization/challenge-induced AR in guinea pigs through regulating the allergic inflammatory response.

\section{Methods}

Animals

Male Hartley guinea pigs (290-310 g) were purchased from Samtako Co. Ltd. (Gyeonggido, Republic of Korea). The animals were housed under controlled environmental conditions at a temperature of $19-25^{\circ} \mathrm{C}$ with a relative humidity of $50-60 \%$ and $12 \mathrm{~h}$ light/dark cycle throughout the study. The care and treatment of animals were in accordance with the guidelines established by the Korean National Institute of Health at the Korean Academy of Medical Sciences for the care and use of laboratory animals and were approved by the Institutional Animal Care and Use Committee of Dongguk University.

\section{Preparation of $\mathrm{KOB} 03$}

Herbs used in KOB03 were purchased from the Medicinal Materials Company (Kwangmyungdang Medicinal Herbs, Ulsan, South Korea). All herbs were authenticated by Professor Y.-K. Park, a medical botanist in the Department of Herbology, College of Oriental Medicine, Dongguk University (DUCOM), Republic of Korea. Voucher specimens were deposited in the Herbarium of the DUCOM under registration number 2011-GMPKOB03-11003. Dried extract of KOB was received from
Hanpoong Pharm \& Food Co., Ltd. (Jeonju, Korea). Briefly, herbs of KOB03 were mixed according to the ratios in Table 1, minced with a grinder, extracted with $2000 \mathrm{~mL}$ of boiling water $\left(95-100^{\circ} \mathrm{C}\right)$ for $4 \mathrm{~h}$, and filtered through $50 \mu \mathrm{m}$ and $1 \mu \mathrm{m}$ cartridge paper. The filtered extract was concentrated in a rotary evaporator (Hanpoong Pharm \& Food Co., Ltd., Jeonju, Korea) at $60^{\circ} \mathrm{C}$ for $15 \mathrm{~h}$ with $700 \mathrm{mmHg}$, and the concentrated extract was vacuum-dried (yield: $20.0 \mathrm{~kg}, 40 \%$ ).

\section{Preparation of AR guinea pig model}

The guinea pigs were divided into five groups $(n=10$ per group) as follows: normal group, OVA-sensitized/ challenged group as a control, OVA-sensitized/challenged group with KOB03 at dose of $200 \mathrm{mg} / \mathrm{kg}$ or $500 \mathrm{mg} / \mathrm{kg}$, and OVA-sensitized/challenged group with ketotifen at a dose of $10 \mathrm{mg} / \mathrm{kg}$ as a reference drug. Guinea pigs were given free access to a standard laboratory diet and water during the experimental period. OVA solution $(1 \mathrm{mg} / \mathrm{mL}$ in saline) and $\mathrm{Al}(\mathrm{OH})_{3}(20 \mathrm{mg} / \mathrm{mL}$ in saline) were mixed in a 1 to 1 ratio and then mice were sensitized with an intraperitoneal injection on days 0,7 , and 14 (Figure 1). On the seventh day after the last sensitization, the guinea pigs were locally challenged by instilling $0.2 \%$ OVA solution $(0.04 \mathrm{~mL} /$ guinea pig) into the bilateral nasal cavities using a micropipette three times from day 21 to day 28 . KOB03 at a dose of 200 or $500 \mathrm{mg} / \mathrm{kg}$ body weight or ketotifen at a dose of $10 \mathrm{mg} / \mathrm{kg}$ body weight, was orally administered to OVA-sensitized animals once daily for 7 consecutive days during OVA challenge. Normal and OVA-sensitized/ challenged animals were given saline alone on the same schedule. Blood samples were taken from each guinea pig by cardiac puncture under isoflurane anesthesia $24 \mathrm{~h}$ after the oral administration of KOB03. The administrated doses of KOB03 were calculated from the guidelines for the determination of human equivalent dose (HED) in clinical applications [12]. Serum was prepared and frozen at $-70^{\circ} \mathrm{C}$ prior to analysis. The nasal tissues were removed from the body and histopathological changes were assessed.

\section{Serological analysis}

The concentrations of histamine, OVA-specific IgE, eosinophil cationic protein (ECP) and cytokines such as TNF- $\alpha$, IL-4, and IFN- $\gamma$ in the sera of guinea pigs were measured by enzyme-linked immunosorbent assay (ELISA)

Table 1 Herbal constituents of KOB03

\begin{tabular}{|c|c|c|c|}
\hline Herbal name & Species & Ratio & Weight (kg) \\
\hline Atractylodis Rhizoma Alba & Atractylodes japonica Koidz & 2 & 15.4 \\
\hline Astragali Radix & Astragalus membranaceus Bunge & 1.5 & 11.5 \\
\hline Peucedani Japonici Radix & Saposhnikovia divaricata Schischkin & 1 & 7.7 \\
\hline Osterici Radix & Ostericum koreanum Maximowicz & 1 & 7.7 \\
\hline Scutellariae Radix & Scutellaria baicalensis Georgi & 1 & 7.7 \\
\hline
\end{tabular}




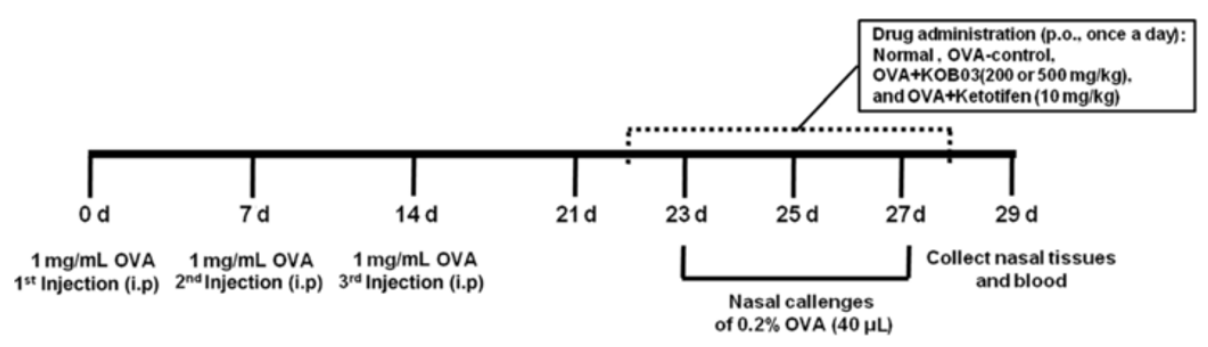

Figure 1 Study plan for the development of an experimental in vivo model of AR.

kits (Wuhan EIAAB Science Co., Ltd., Wuhan, China) or enzyme immunoassay (EIA) kits (Wuhan EIAAB Science Co., Ltd.) according to the manufacturer's recommendations. The concentration of each substance was calculated from the equations obtained from standard curve plots for the standard solutions in the kits.

\section{Histological evaluation of nasal mucosal tissues}

Guinea pigs were euthanized with a high dose of isoflurane (1-4\%) and exsanguinated after final OVA challenge. The head was removed and the lower jaw was discarded. The nasal tissues were separated from the skin, muscle and soft tissue and immersed in freshly prepared $10 \%$ neutral buffered formalin for $48 \mathrm{~h}$. The tissue was then rinsed in running tap water and decalcified in $10 \%$ nitric acid solution for 5 days. After rinsing in tap water, the tissue was processed for dehydration through graded alcohol and embedded in paraffin. Serial sections $(5 \mu \mathrm{m})$ were cut at the level of the incisive papillae and first and second palatal ridges and then stained with hematoxylin and eosin (H\&E), Periodic Acid Schiff (PAS) for goblet cells and Giemsa for eosinophils. Sections were examined under a light microscope (Leica Microsystems $\mathrm{GmbH}$, Wetzlar, Germany).

\section{Immunohistochemistry}

Specimens were embedded in paraffin, cut into 5-mmthick sections and floated onto aminoalkylsilane-coated slides (Polysciences, PA, USA). The sections were deparaffinized and rehydrated through graded alcohol washes. After microwave treatment, the sections were treated with $0.3 \%$ hydrogen peroxide in methanol for $15 \mathrm{~min}$ to inhibit endogenous peroxidase activity of blood cells and with $1 \%$ bovine serum albumin (BSA) in $0.05 \mathrm{M}$ phosphate/0.1 M NaCl, pH 7.4 (PBS) containing blocking reagent for another $10 \mathrm{~min}$ at room temperature. The sections were incubated with a primary antibody against TNF- $\alpha$ at the appropriate concentration (1:100) in PBS with $1 \% \mathrm{BSA}$ for $12 \mathrm{~h}$ or overnight at $4^{\circ} \mathrm{C}$. After thorough washing with PBS containing Triton X-100, each sample was incubated with the secondary antibody $(1: 100)$ in PBS with 1\% BSA for $3 \mathrm{~h}$ at room temperature. After repeated washing, the sections were stained with the $A B C$ kit (Dako, Glostrup, Denmark) that includes DAB for $30 \mathrm{~min}$ at room temperature. After washing, the sections were stained with hematoxylin for $1 \mathrm{~min}$ ( $1 \mathrm{drop}$ ) at room temperature. After another wash, the sections were dehydrated and mounted with a glass coverslip.

High-performance liquid chromatography (HPLC) analysis HPLC analysis for identification of the standard compounds was performed using an HPLC system (Waters, MA, USA) equipped with water 510 pump, waters autoinjector and waters UV/VIS 486 detector. KOB03 powder (1 g) was dissolved in $10 \mathrm{~mL}$ distilled water, extracted with ultrasonic waves for $5 \mathrm{~min}$, and filtered through a $0.2-\mu \mathrm{m}$ PVDF membrane filter. KOB03 $(5 \mathrm{mg} / \mathrm{mL})$ or chlorogenic acid $\left(\mathrm{C}_{16} \mathrm{H}_{18} \mathrm{O}_{9}: 354.31 ; 4 \mathrm{mg}\right)$, methylvisamminol glucoside (4'-O-beta-D-glucopyranosyl-5-O-methylvisamminol, $\mathrm{C}_{22} \mathrm{H}_{28} \mathrm{O}_{10}: 452.46 ; 5 \mathrm{mg}$ ), calycosin glucoside (calycosin7-O- $\beta$-D-glucoside, $\mathrm{C}_{22} \mathrm{H}_{22} \mathrm{O}_{10}: 446.1 ; 1 \mathrm{mg}$ ), and baicalin $\left(\mathrm{C}_{21} \mathrm{H}_{18} \mathrm{O}_{11}\right.$ : 446.37; $\left.21 \mathrm{mg}\right)$ as standard compounds were dissolved in $1 \mathrm{~mL}$ of $100 \%$ methanol for pattern analysis using HPLC with a photodiode array detector (Waters, Milford, MA, USA). Chromatographic separation was carried out using an Optimapak $\mathrm{C}_{18}(4.6 \times 250 \mathrm{~mm}, 5 \mu \mathrm{m})$ at room temperature. For analysis of chlorogenic acid, methylvisamminol glucoside, and calycosin glucoside, the injection volume was $10 \mu \mathrm{L}$ and the following solvent ratios were used for the mobile phase with a flow rate of $1.0 \mathrm{~mL} / \mathrm{min}$, where solvent $\mathrm{A}$ was $0.5 \%$ acetic acid in water and solvent $\mathrm{B}$ was $0.5 \%$ acetic acid in methanol: $0 \mathrm{~min}$, $25 \% \mathrm{~B} ; 10 \mathrm{~min}, 32 \% \mathrm{~B} ; 20 \mathrm{~min}, 45 \% \mathrm{~B} ; 24 \mathrm{~min}, 48 \% \mathrm{~B}$; $35 \mathrm{~min}, 48 \% \mathrm{~B}$; $40 \mathrm{~min}, 25 \% \mathrm{~B}$; and $45 \mathrm{~min}, 25 \% \mathrm{~B}$. For analysis of baicalin, the injection volume was $10 \mu \mathrm{L}$ and the following solvent ratios were used for the mobile phase with a flow rate of $1.0 \mathrm{~mL} / \mathrm{min}$, where solvent $\mathrm{A}$ was $1 \%$ acetic acid in water and solvent $\mathrm{B}$ was $1 \%$ acetic acid in methanol: $0 \mathrm{~min}, 30 \% \mathrm{~B} ; 42 \mathrm{~min}, 65 \% \mathrm{~B} ; 44 \mathrm{~min}$, $30 \% \mathrm{~B}$; and $60 \mathrm{~min}, 30 \% \mathrm{~B}$. The detection wavelength (230 nm for chlorogenic acid, methylvisamminol glucoside, and calycosin glucoside or $277 \mathrm{~nm}$ for baicalin) was scanned at a flow rate of $1 \mathrm{~mL} / \mathrm{min}$ at $40^{\circ} \mathrm{C}$. The peak analysis and assignment were performed using the standard compounds, which were identified in accordance 
with their UV spectra and retention time in the HPLC chromatogram.

\section{Statistical analysis}

Data were expressed as means \pm standard deviation (SD). Statistical significance was analyzed with one-way analysis of variance (ANOVA), pair-wise and multiple-comparison testing between groups, as well as the Turkey test using GraphPad Prism 5.0 software (GraphPad software, Inc., CA, USA) followed by Dunnet test for individual comparisons. Differences with $P<0.05$ were considered statistically significant.

\section{Results}

\section{Allergic mediators}

To demonstrate the effect of КОВ03 on allergic responses in vivo, we measured the levels of allergic mediators, histamine, OVA-specific IgE, and ECP in the sera of OVA sensitization/challenge-induced AR guinea pigs. Sensitization/challenge of OVA in guinea pigs induced a significant increase in the production of histamine (Figure 2A; $P=0.0044$ ), OVA-specific IgE (Figure 2B;
$P=0.0019$ ) and ECP (Figure 2C; $P=0.0033$ ) compared with the normal group. The administration of KOB03 at doses of 200 and $500 \mathrm{mg} / \mathrm{kg}$ significantly decreased the serum levels of histamine $(P=0.003$ and $P=0.001$, respectively), OVA-specific $\operatorname{IgE}(P=0.0005$ and $P=0.0017$, respectively) and ECP $(P=0.0016$ and $P=0.0008$, respectively) compared with the control group. The inhibitory effect of $\mathrm{KOBO} 3$ on the production of allergic mediators was similar to those of the ketotifen-administered group. These data indicate that KOB03 might have anti-allergic activity by suppressing the production of allergic mediators in AR.

\section{Th1 and Th2 cytokines}

To investigate the effect of КОВ03 on the cytokine balance in vivo, we measured the serum levels of a Th1 cytokine, IFN- $\gamma$ and a Th2 cytokine, IL- 4 by ELISA. Sensitization/challenge of OVA in guinea pigs significantly increased the level of IL-4 (Figure 3A; $P=0.005$ ), and significantly decreased the level of IFN- $\gamma$ (Figure 3B; $P=0.0001$ ) compared with the normal group. The administration of KOB03 at doses of 200 and $500 \mathrm{mg} / \mathrm{kg}$

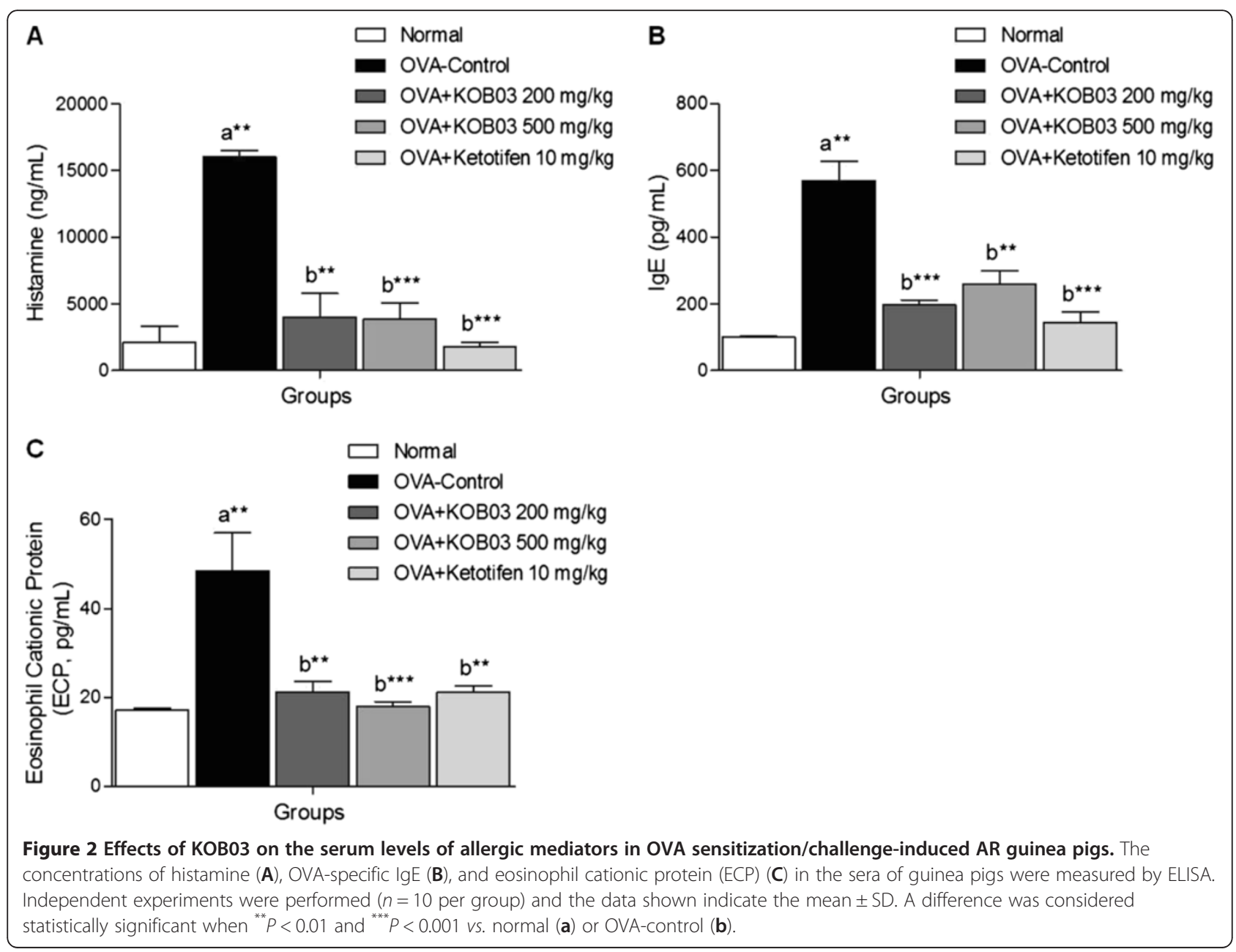



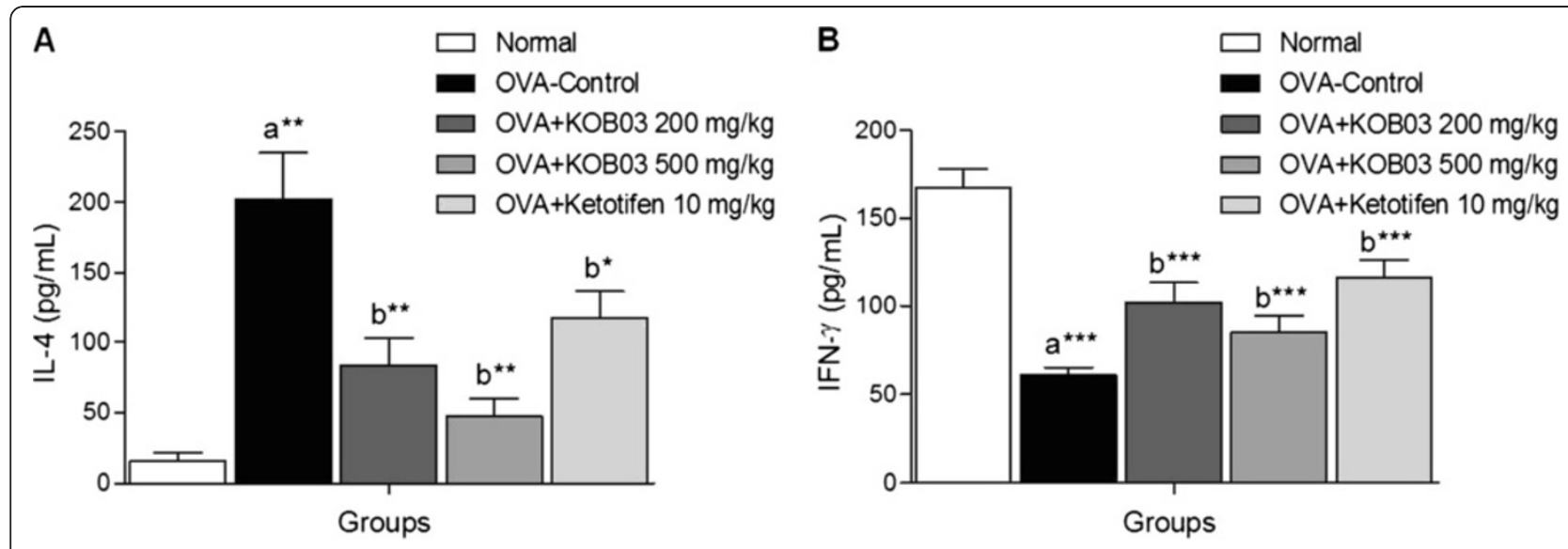

Figure 3 Effects of КОВ03 on the serum levels of cytokines in OVA sensitization/challenge-induced AR guinea pigs. The concentrations of IL-4 (A) and IFN- $\gamma(\mathbf{B})$ in the sera of guinea pigs were measured by ELISA. Independent experiments were performed $(n=10$ per group), and the data shown indicate the mean \pm SD. A difference was considered statistically significant when ${ }^{*} P<0.05{ }^{* *} P<0.01$ and ${ }^{* * *} P<0.001$ vs. normal (a) or OVA-control (b).

significantly decreased the IL-4 levels $(P=0.0058$ and $P=0.0017$, respectively), while significantly increasing the IFN- $\gamma$ levels $(P=0.0001$ and $P=0.0006$, respectively) compared with the OVA control group. The regulatory effect of KOB03 on the production of IL-4 and IFN- $\gamma$ was superior to that of the ketotifen-treated group. These data indicate that KOB03 might control the Th1/ Th2 balance in AR.

\section{Histological changes of nasal tissues}

Sensitization/challenge of OVA in guinea pigs induced histological changes in the nasal mucosa such as epithelial disruption with mucosa thickening and regional thinning of the epithelium (Figure 4, H\&E), the hyperplasia of goblet cells containing mucus (Figure 4) and infiltration of numerous inflammatory cells into the nasal mucosa (Figure 5). The administration of KOB03 at doses of 200 and $500 \mathrm{mg} / \mathrm{kg}$ inhibited the nasal destruction and the hyperplasia of mucin-producing goblet cells in OVA-sensitized/challenged guinea pigs. Furthermore, the administration of KOB03 at a dose of $500 \mathrm{mg} / \mathrm{kg}$ significantly decreased the numbers of infiltrating eosinophils into the nasal mucosa $(P=0.0092)$ compared with the OVA control group. The inhibitory effect of KOB03 on eosinophil

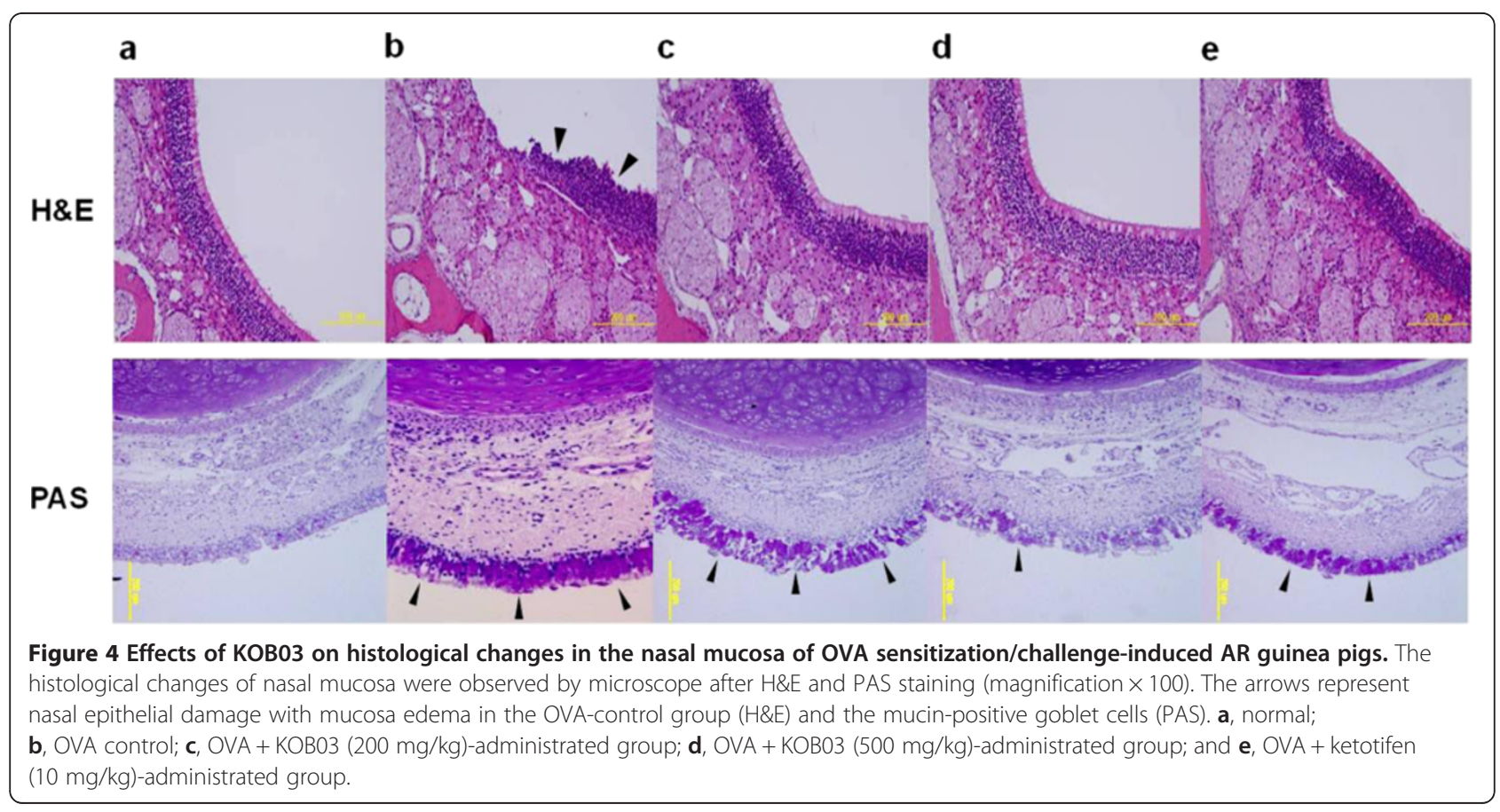




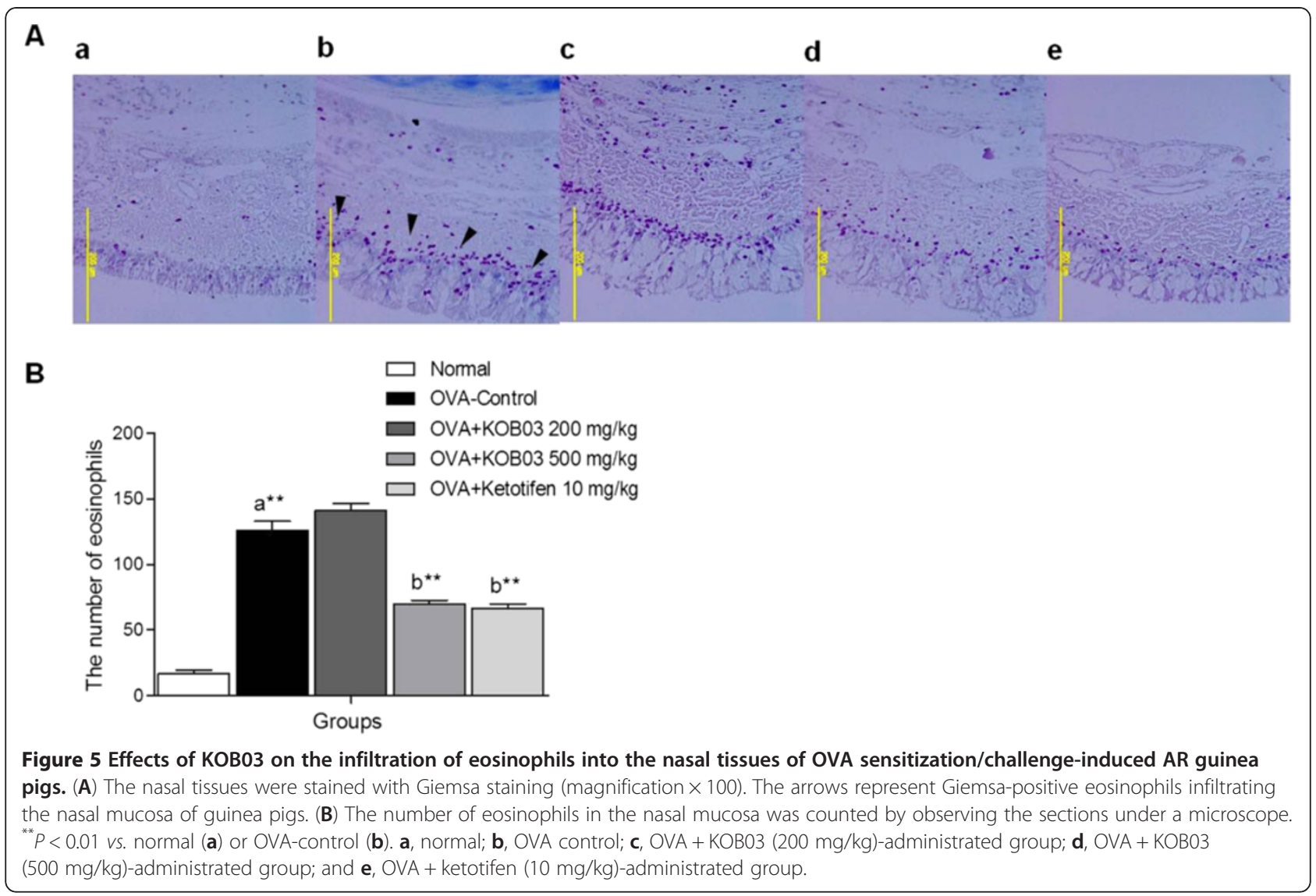

infiltration was similar to that in the ketotifen-treated group. These data indicate that $\mathrm{KOB} 03$ might prevent nasal destruction by allergic inflammation during AR.

\section{TNF-a expression in nasal tissues}

To evaluate the effect of KOB03 on allergic inflammation, we measured the level of TNF- $\alpha$ in the serum of OVA sensitization/challenge-induced AR guinea pigs by ELISA (Figure 6A), and determined its expression level in the nasal mucosa by immunohistochemistry (Figure 6B). Sensitization/challenge of OVA significantly decreased the level of TNF- $\alpha$ in the sera of guinea pigs (Figure 5A; $P=0.0007)$ compared with the normal group. The administration of KOB03 at doses of 200 and $500 \mathrm{mg} / \mathrm{kg}$ significantly decreased the level of TNF- $\alpha(P=0.0002$ and $P=0.0003$, respectively) in the sera of OVA-sensitized/ challenged guinea pigs compared with the OVA-control group. In addition, the administration of $\mathrm{KOB} 03$ at doses of 200 and $500 \mathrm{mg} / \mathrm{kg}$ remarkably suppressed the expression of TNF- $\alpha$ in the nasal mucosa and were more effective for TNF- $\alpha$ inhibition than ketotifen (Figure 5B).

\section{HPLC analysis}

In HPLC analysis of KOB03, the peak assignment was based on the standard compounds, chlorogenic acid, calycosin glucoside, methylvisamminol glucoside, and baicalin in a HPLC chromatogram. Baicalin was identified as the main compound of KOB03 (Figure 7A), and three compounds were also detected in the HPLC analysis (Figure 7B).

\section{Discussion}

Instead of allergen avoidance and environmental control, manipulation of mediator release from airway epithelial cells is the main therapeutic target for managing AR. In addition, treatment strategies have aimed to either reduce the effects of mediators from activated cells in the sensory neural and vascular end organs, or to reduce the tissue accumulation of activated cells that generate inflammatory mediators [5,13]. Although second-generation antihistamines and anticholinergic agents, intranasal corticosteroids and mast cell stabilizers are under development for pharmacotherapy of allergic diseases such as asthma and rhinitis, adverse effects and low clinical efficacy remain $[1,2]$.

Traditional medicines, including complementary, alternative and herbal medicines that improve multi-factorial diseases such as allergic diseases, are considered a good treatment paradigm [14]. KOB03 is a polyherbal medicine derived from herbal prescriptions in oriental clinics, 


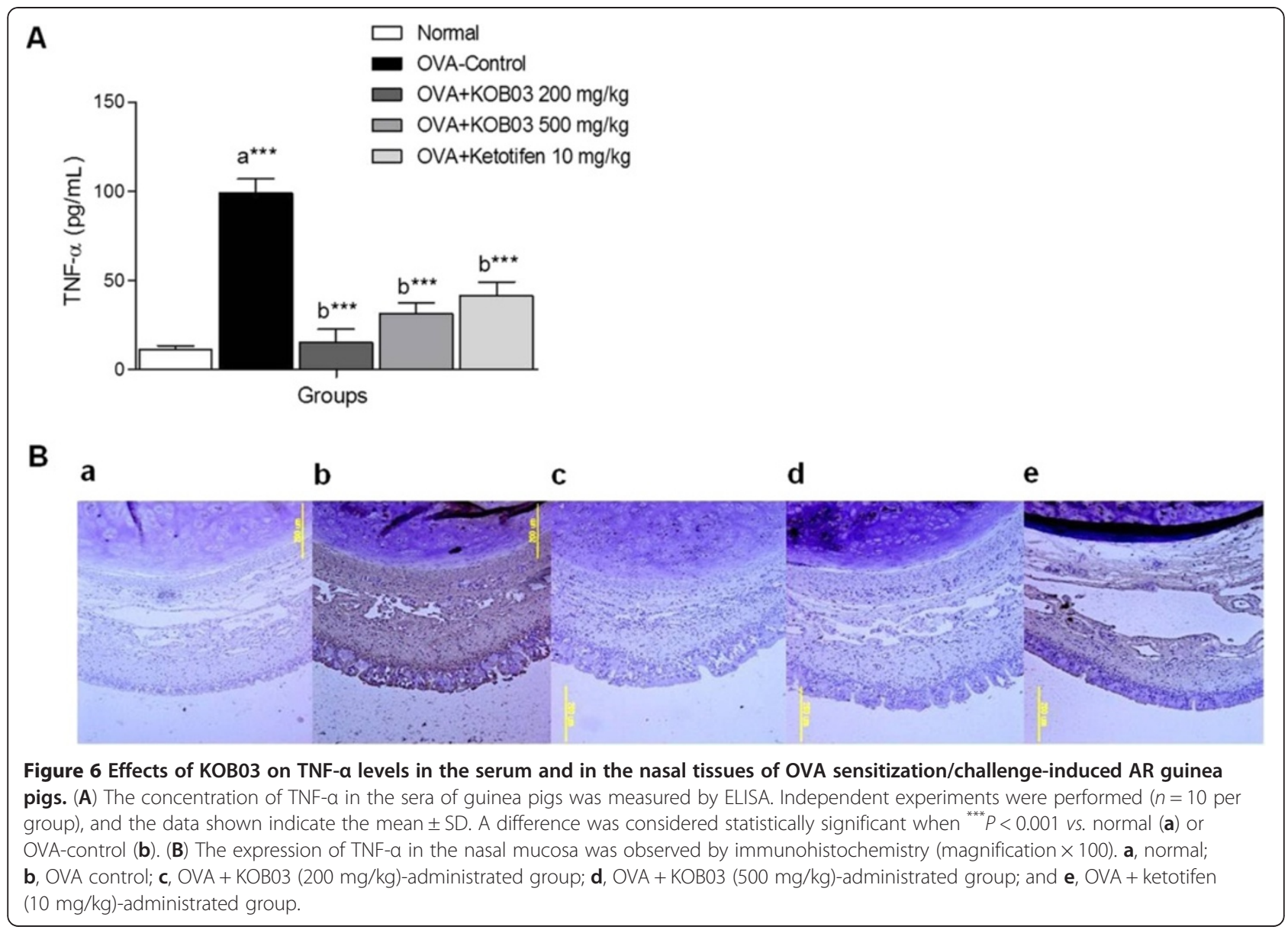

and is a promising candidate for anti-allergic and antiinflammatory effects in acute and chronic allergic diseases $[9,10]$. We previously reported that the anti-allergic effect of KOB03 might be due to suppression of mast cellmediated allergic inflammation [15]. In the present study, we verified that KOB03 had a therapeutic effect on allergic responses in OVA-induced AR in guinea pigs. Among animal models of allergic diseases such as asthma and rhinitis, the guinea pig model of allergic conjunctivitis has proved to be a valid model for the assessment of antiallergic effects of established and newly developed drugs, especially those targeting mast cell mediators [16].

Sensitization/challenge of OVA in guinea pigs led to increases in serum levels of histamine and antigenspecific IgE and the infiltration of inflammatory cells such as eosinophils in the epithelium and subepithelium of the nasal mucosa [5]. Nasal symptoms of AR are mediated by histamine and inflammatory mediators such as prostaglandins, leukotrienes, trypase and proinflammatory cytokines secreted from activated mast cells, eosinophils and basophils [3,17]. Mast cell-derived mediators collectively induce acute-phase clinical symptoms by enhancing vascular leakage, bronchospasm and activation of nociceptive neurons linked to parasympathetic reflex [18].
In this study, КОВ03 markedly inhibited the release of allergic mediators such as histamine and antigen-specific IgE in OVA-sensitized/challenged guinea pigs. These results demonstrated that KOB03 could manage allergic reactions by suppressing mast cell activation in AR similar to the ketotifen-treated group. Ketotifen is a second-generation noncompetitive $\mathrm{H} 1$-antihistamine and mast cell stabilizer that helps sufferers of asthma and rhinitis [19].

Eosinophils are inflammatory cells involved in AR [20]. Eosinophils from allergic subjects are primed in vivo during allergen challenge, and show increased migratory responses, adhesiveness, degranulation and an altered oxidative mechanism $[21,22]$. Upon allergen challenge, eosinophils recruited to several organs such as lungs, nose, skin and eyes, and biological fluids, induce the release of oxygen radicals, newly generated mediators such as platelet-activating factor, leukotrienes (LT) $\mathrm{C}_{4}$, and ECP [21]. Therefore, eosinophils may be responsible for basic histopathologic changes of target tissues causing vasodilation, mucosal edema, epithelial cell damage, and nonspecific hyperreactivity [23]. ECP is a major basic and potentially cytotoxic granule protein secreted by eosinophils. In this study, the administration of KOB03 significantly inhibited the infiltration of eosinophils into the nasal 
A

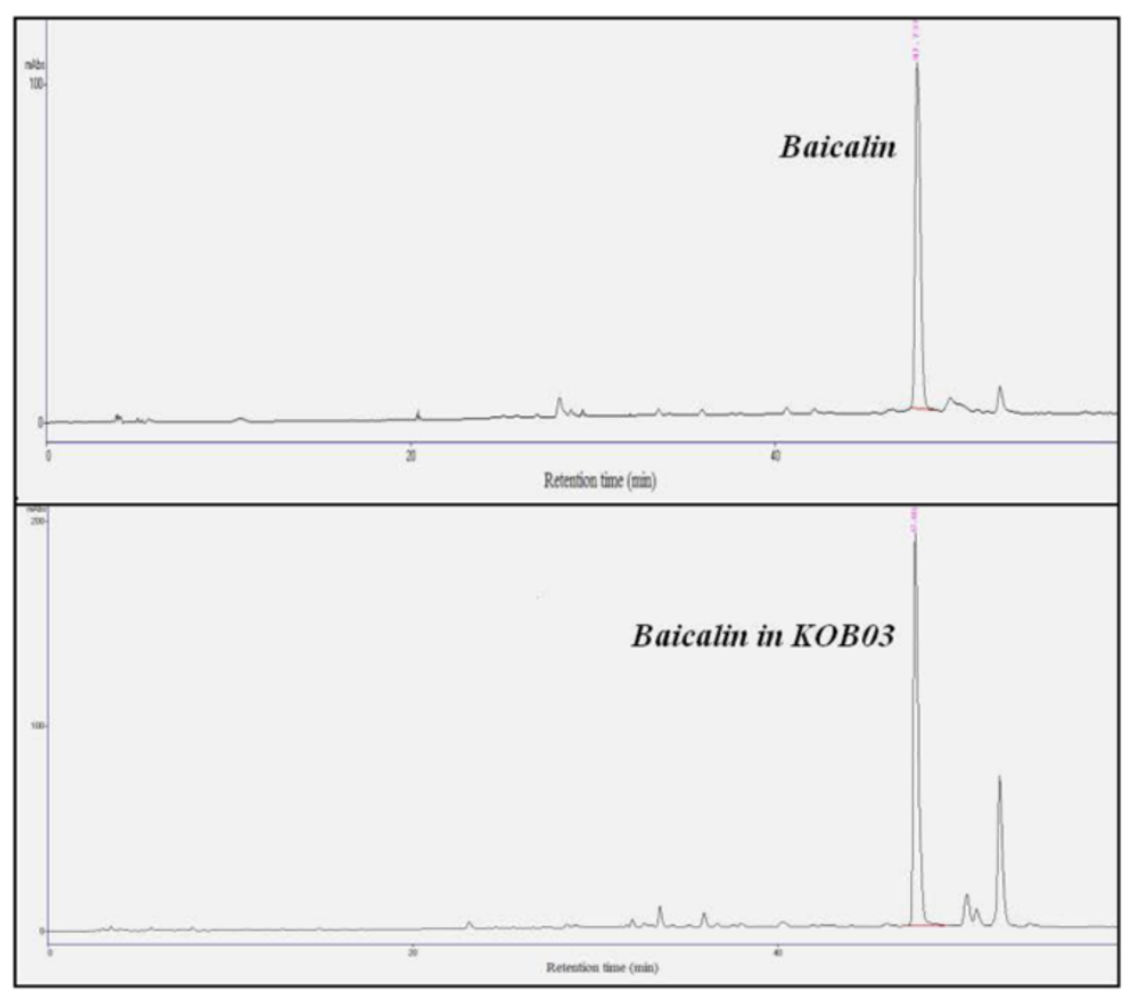

B

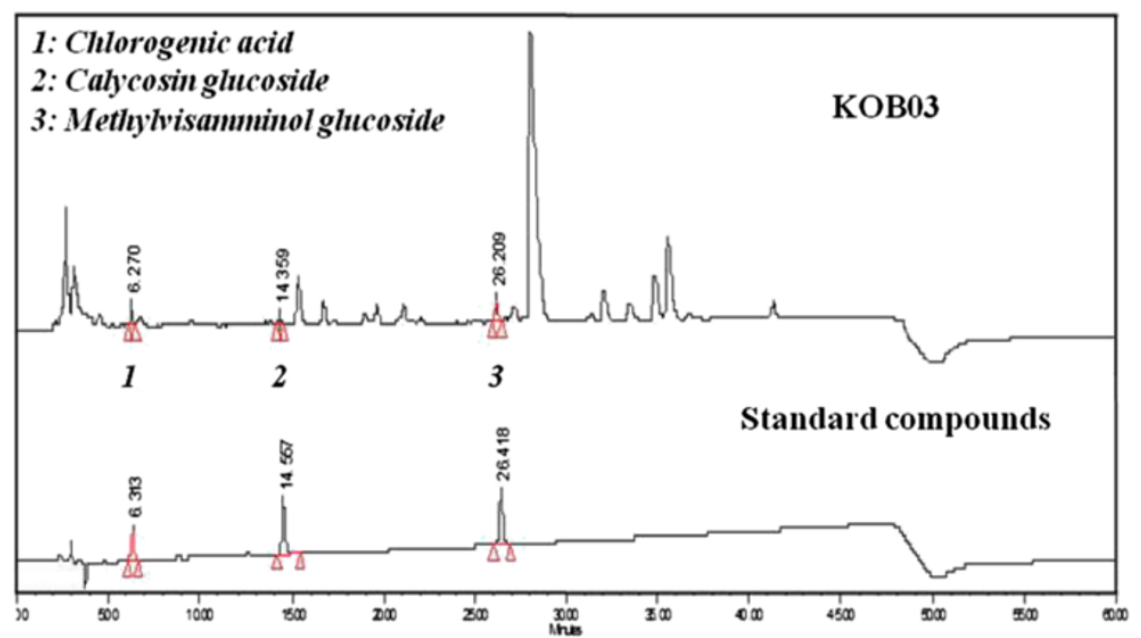

Figure 7 HPLC pattern analysis of KOB03. (A) HPLC pattern with baicalin. (B) HPLC pattern with chlorogenic acid, calycosin glucoside, and methylvisamminol glucoside.

mucosa and decreased the release of ECP from activated eosinophils after sensitization/challenge of OVA in guinea pigs. This suggested that KOB03 protected guinea pigs against allergen-induced allergic immune responses of AR by suppressing the activation of eosinophils.

The pathogenesis of AR involves the allergen-induced proliferation of Th2 lymphocytes secreting IL-3, IL-4, IL-5, IL-9 and IL-13. These cytokines promote IgE production, eosinophil activation and mast cell proliferation
[24]. During sensitization, antigen processing by antigenpresenting cells, including dendritic cells, regulates $\mathrm{T}$ cell activation, production of specific cytokines and isotype switching. Specific IgE production from B cells mediated by IL-4, is a critical step in the allergic cascade $[4,5]$. In the present study, the administration of KOB03 significantly inhibited the production of IL-4 in the sera of OVA-sensitized/challenged guinea pigs and inhibited the infiltration of inflammatory cells, eosinophils in the 
epithelium and subepithelium of the nasal mucosa. This implied that KOB03 might control the imbalance of Th1/ Th2 cytokines in AR. Allergic mucosal inflammation characterized by the tissue infiltration of inflammatory cells such as eosinophils, basophils, and neutrophils is associated with the activation of mast cells and T cells.

Proinflammatory cytokines such as TNF- $\alpha$ and IL-1 $\beta$ are potent multifunctional cytokines in the pathogenesis of many inflammatory diseases, including asthma and rhinitis [25]. These cytokines are produced by a variety of cells in the airways and are released by the IgEdependent activation of mast cells [16]. TNF- $\alpha$ is related to the pathogenesis of these events by upregulating the expression of endothelial cell adhesion molecules, mediating granulocyte chemoattraction, and activating eosinophils, mast cells and T cells [26]. Recent studies [27,28] show that TNF- $\alpha$ may be associated with acquired airway hyperresponsiveness, a pathophysiological hallmark of allergic and inflammatory diseases and can induce the transepithelial migration of neutrophils by IL-8 production and the upregulation of adhesion molecules. In this study, administration of $\mathrm{KOB} 03$ significantly decreased the serum level of TNF- $\alpha$ and inhibited its expression in the nasal mucosa of OVA-sensitized/challenged guinea pigs. This suggests that KOB03 might suppress allergic inflammation by the down-regulation of TNF- $\alpha$ expression in $A R$

KOB03 is a decoction of five herbs with different pharmacological actions, and the main compound, baicalin, has been identified by HPLC analysis as a standard compound. Baicalin, a flavonoid extracted from various herbal plants, is reported to have antiallergic properties in atopic dermatitis [29], type IV allergic reactions [30], IgE-mediated allergic reactions [31], and anaphylaxis [32]. In addition, three minor compounds, chlorogenic acid as a standard compound of Osterici radix, calycosin glucoside as a standard compound of Astragali radix and methylvisamminol glucoside as a standard compound of Saposhnikoviae Radix were also identified in KOB03 by HPLC analysis. Chlorogenic acid is reported to have antiallergic properties on mast cell-dependent anaphylactic responses in rats [33]. The ability of КОВ03 to control the allergic inflammatory response in AR was a result of the synergistic antiallergy and anti-inflammatory effects of its constituents' components. Although KOB03 has therapeutic potential against AR in vivo, further studies should be conducted to identify the active compounds of KOB03 and the mechanism of action of the antiallergy properties.

\section{Conclusion}

The present study demonstrated that KOB03 has therapeutic potential in AR by inhibiting nasal obstruction and the release of inflammatory mediators such as histamine, allergen-specific IgE, and ECP and modulating the imbalance of Th1/Th2 cytokines in OVA sensitization/ challenge-induced AR guinea pigs. These results suggest that KOB03 might be developed as a promising natural medicine for the treatment of allergic rhinitis.

\section{Abbreviations}

AR: Allergic rhinitis; OVA: Ovalbumin; ECP: Eosinophil cationic protein; IgE: Immunoglobulin E.

\section{Competing interests}

The authors declare that they have no competing interests.

\section{Authors' contribution}

YKP performed botanical evaluation, wrote and revised the manuscript. HWJ conducted histological evaluation statistical analysis. JKJ conducted pharmacological studies. YHK and JSK performed extraction and HPLC pattern analysis. All authors read and approved the final manuscript.

\section{Acknowledgements}

This work was supported by grants from the Ministry of Health and Welfare, Republic of Korea, for the development of herbal medicine drugs for allergic rhinitis (F090002, To. Y.-K. Park).

\section{Author details}

'Oriental Medicine R\&D Center, Dongguk University, Gyeongju 780-714, Republic of Korea. '2Department of Herbology, College of Oriental Medicine, Dongguk University, Seokjang-Dong 707, Gyeongju 780-714, Republic of Korea. ${ }^{3}$ College of Pharmacy, Chungnam National University, Daejeon 305-764, Republic of Korea.

Received: 11 August 2012 Accepted: 19 December 2012 Published: 20 December 2012

\section{References}

1. Mygind N: Glycocorticosteroids and rhinitis. Allergy 1993, 48:476-490.

2. Bousquet J, Van Cauwenberge P, Khaltaev N, Aria Workshop Group, World Health Organization: Allergic rhinitis and its impact on asthma. J Allergy Clin Immunol 2001, 108:S147-S334.

3. Shinmei $Y$, Yano H, Kagawa $Y$, Izawa K, Akagi M, Inoue $T$, Kamei C: Effect of Brazilian propolis on sneezing and nasal rubbing in experimental allergic rhinitis of mice. Immunopharmacol Immunotoxicol 2009, 31:688-693.

4. Pawankar R, Mpro S, Ozu C, Kimura S: Overview on the pathomechanisms of allergic rhinitis. Asia Pac Allergy 2011, 1:157-167.

5. Quraishi SA, Davies MJ, Craig TJ: Inflammatory responses in allergic rhinitis: traditional approaches and novel treatment strategies. J Am Osteopath Assoc 2004, 104:S7-S15.

6. Nguyen TH, Casale TB: Immune modulation for treatment of allergic disease. Immunol Rev 2011, 242:258-271.

7. Li XM, Srivastava K: Traditional Chinese medicine for the therapy of allergic disorders. Curr Opin Otolaryngol Head Neck Surg 2006, 14:191-196.

8. Heo J: Dongui Bogam. Republic of Korea: Dae Sung Publisher Co; 1985:123.

9. Kim CM, Heo MY, Kim HP, Sin KS, Pachaly P: Pharmacological activities of water extracts of Umbelliferae plants. Arch Pharm Res 1991, 14:87-92.

10. Na HJ, Jeong HJ, Hong SH, Hwang CY, Cha WS, Kim HM: Effect of Boo Yong-Tang on mast cell-mediated allergic reaction. Immunopharmacol Immunotoxicol 2004, 26:445-454.

11. Shin S: In vitro effects of essential oils from Ostericum koreanum against antibiotic-resistant Salmonella spp. Arch Pharm Res 2005, 28:765-769.

12. Cox Gad S, Sonu Sundd S: Preclinical Development Handbook, Toxicology, Toxicokinetics, An integral component of preclinical toxicity studies. Hoboken: John Wiley \& Sons, Inc; 2008:487.

13. Al Suleimani YM, Walker MJ: Allergic rhinitis and its pharmacology. Pharmacol Ther 2007, 114:233-260.

14. Resnick ES, Bielory BP, Bielory L: Complementary therapy in allergic rhinitis. Curr Allergy Asthma Rep 2008, 8:118-125.

15. Jung HW, Jung JK, Cho CW, Kang JS, Park YK: Antiallergic effect of KOBO3, a polyherbal medicine, on mast cell-mediated allergic responses in ovalbumin-induced allergic rhinitis mouse and human mast cells. J Ethnopharmacol 2012, 142:684-693. 
16. Groneberg DA, Bieloy L, Fischer A, Bonini S, Wahn U: Animal models of allergic and inflammatory conjunctivitis. Allergy 2003, 58:1101-1113.

17. Martynova MG, Bystrova OA, Moiseeva OM, Evdonin AL, Kondratov KA, Medvedeva ND: The presence of ANP in rat peritoneal mast cells. Cell Res $2005,15: 811-816$.

18. Zhang HQ, Sun Y, Xu F: Therapeutic effects of interleukin-1 receptor antagonist on allergic rhinitis of guinea pig. Acta Pharmacol Sin 2003, 24:251-255.

19. Sur DK, Scandale S: Treatment of allergic rhinitis. Am Fam Physician 2010, 81:1440-1446.

20. Woschnagg C, Rubin J, Venge P: Eosinophil cationic protein (ECP) is processed during secretion. J Immunol 2009, 183:3949-3954.

21. Tomassini M, Magrini L, De Petrillo G, Adriani E, Bonini S, Balsano F, Bonini S: Serum levels of eosinophil cationic protein in allergic disease and natural allergen exposure. J Allergy Clin Immunol 1996, 97:1350-1355.

22. Håkansson L, Heinrich C, Rak S, Venge P: Priming of eosinophil adhesion in patients with birch pollen allergy during pollen season: effect of immunotherapy. J Allergy Clin Immunol 1997, 99:551-562.

23. Bousquet J, Chanez P, Campbell AM, Lacoste JY, Poston R, Enander I, Godard P, Michel FB: Inflammatory processes in asthma. Int Arch Allergy Appl Immunol 1991, 94:227-232.

24. Jones N: Allergic rhinitis: aetiology, predisposing and risk factors. Rhinology 2004, 42:49-56.

25. Grzelewska-Rzymowska I, Pietrzkowicz M: Role of tumor necrosis factoralpha in allergic inflammation and airway hyperresponsiveness. Pol Merkur Lekarski 2004, 16:173-178.

26. Bradding P, Feather $\mathrm{IH}$, Wilson S, Bardin PG, Heusser CH, Holgate ST, Howarth PH: Immunolocalization of cytokines in the nasal mucosa of normal and perennial rhinitic subjects. The mast cell as a source of IL-4, IL-5, and IL-6 in human allergic mucosal inflammation. J Immunol 1993, 151:3853-3865.

27. Bradding P, Mediwake R, Feather IH, Madden J, Church MK, Holgate ST, Howarth PH: TNF alpha is localized to nasal mucosal mast cells and is released in acute allergic rhinitis. Clin Exp Allergy 1995, 25:406-415.

28. Wilson SJ, Lau L, Howarth PH: Inflammatory mediators in naturally occurring rhinitis. Clin Exp Allergy 1998, 28:220-227.

29. Yun MY, Yang JH, Kim DK, Cheong KJ, Song HH, Kim DH, Cheong KJ, Kim Yl, Shin SC: Therapeutic effects of Baicalein on atopic dermatitis-like skin lesions of NC/Nga mice induced by dermatophagoides pteronyssinus. Int Immunopharmacol 2010, 10:1142-1148.

30. Taniguchi C, Homma M, Takano O, Hirano T, Oka K, Aoyagi Y, Niitsuma T, Hayashi T: Pharmacological effects of urinary products obtained after treatment with saiboku-to, a herbal medicine for bronchial asthma, on type IV allergic reaction. Planta Med 2000, 66:607-611.

31. Kimata $\mathrm{M}$, Inagaki $\mathrm{N}$, Nagai $\mathrm{H}$ : Effects of luteolin and other flavonoids on IgE-mediated allergic reactions. Planta Med 2000, 66:25-29.

32. Koda A, Nagai H, Wada H: Pharmacological actions of baicalin and baicalein. 2. On passive anaphylaxis. Nihon Yakurigaku Zasshi 1970, 66:237-247.

33. Qin HD, Shi YQ, Liu ZH, Li ZG, Wang HS, Wang H, Liu ZP: Effect of chlorogenic acid on mast cell-dependent anaphylactic reaction. Int Immunopharmacol 2010, 10:1135-1141.

doi:10.1186/1749-8546-7-27

Cite this article as: Jung et al: Effect of $\mathrm{KOBO3}$, a polyherbal medicine, on ovalbumin-induced allergic rhinitis in guinea pigs. Chinese Medicine 2012 7:27.

\section{Submit your next manuscript to BioMed Central and take full advantage of:}

- Convenient online submission

- Thorough peer review

- No space constraints or color figure charges

- Immediate publication on acceptance

- Inclusion in PubMed, CAS, Scopus and Google Scholar

- Research which is freely available for redistribution 